\title{
CONCEPTS AND NEW PERSPECTIVES FOR LONG SPAN BRIDGES
}

Fabio Brancaleoni, full professor of Structural Engineering, University of Rome TRE

\section{Abstract}

A discussion of the dominant factors affecting the behaviour of long span cable supported bridges is the subject of this paper. The main issue is the evolution of properties and response of the bridge with the size of the structure, represented by the critical parameter of span length, showing how this affects the conceptual design. After a review of the present state of the art, perspectives for future developments are discussed.

Keywords: Cable supported bridges, long span bridges, aeroelasticity

\section{INTRODUCTION}

The last decades have witnessed significant steps in the evolution of long span cable supported bridges, where high strength steel wires are still the fundamental structural element, formed into cables, strands or ropes, with new materials still not mature for large scale adoption [1]. More recent and rapid the increase of span achieved by cable stayed schemes that have more than doubled their maximum span in thirty years, passing from the $465 \mathrm{~m}$ of the Fraser Bridge (1986, British Columbia) to the $1104 \mathrm{~m}$ of the Russkij Bridge (2012, Russia), not to speak of the daring hybrid design for the 1408 m span of the Sultan Selim or Third Bosphorus Bridge presently in construction (Turkey, completion 2016).

Seemingly less significant the progress of suspension bridges: the record span in the eighties was the 1410 m Humber Bridge (UK, 1981), while the maximum present span is still the almost 20 years old 1991 m Akashi Kaikyo Bridge (Japan), whose construction started in the late eighties and was completed in 1998.

Though, in the above scenario it must be said that cable stayed bridges will probably not undergo in the next years a further development of the same magnitude [2]: the present spans are close to being limited by a number of effects, among them the main ones being the erection stages, that imply large 
structural sizes for the compressed area of the deck and a significant sensitivity to both static and dynamic wind effects, the progressively larger structures needed for anchoring the side span stays, the height necessary for the towers, the more and more complex challenge of controlling the various possible forms of dynamic wind response of long stays [3].
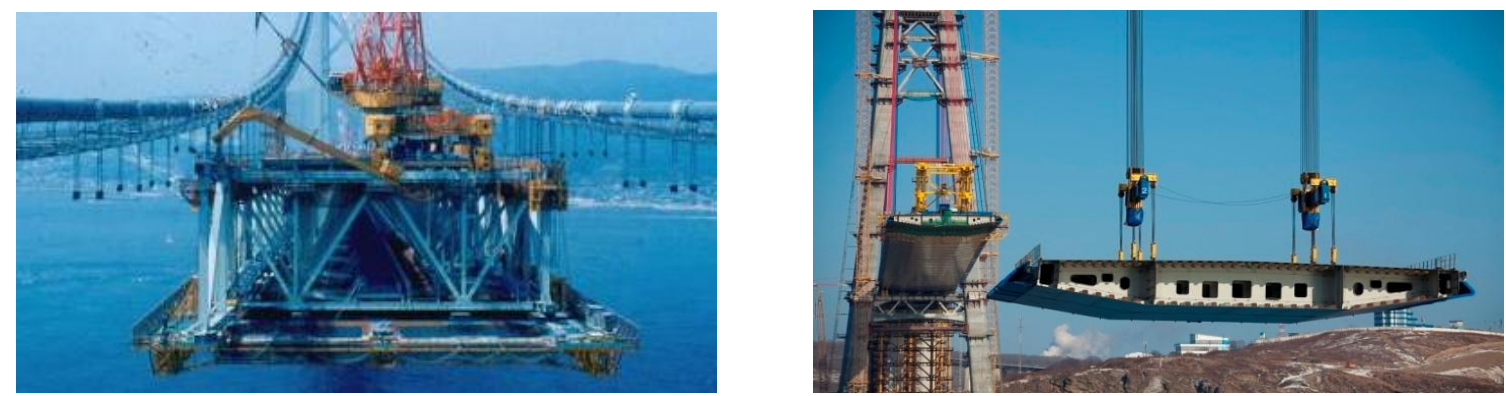

Figure 1. The longest suspension and cable stayed bridges today: Akashi Kaikyo (left) and Russkij (right)

Super long spans shall hence be, in the view of the author, still the domain of suspension bridges in the next years [4]. The purpose of this paper is to highlight the characteristics and limits of the present suspension bridge solutions and technologies, outlining new concepts and attempting to answer a question always present in the hearth of engineers: what shall the future bring ?

\section{SUSPENSION BRIDGES, THE PROBLEM OF SCALE}

A suspension bridge is a fundamentally simple structure: traffic loads are applied to the deck, carried to the main cable through the hangers and subsequently brought to ground through the towers for the vertical component and through the anchor blocks for the horizontal one (Figure 2).

When subject to live loads a suspension bridge undergoes an interaction in which forces are carried through the structure depending on the relative stiffness of the different elements involved. The primary interaction is that between the deck, whose stiffness is mainly related to flexure, and the main cables, whose stiffness is instead mainly geometric and in turn dependent upon the tensile load present and for this reason often referred to as "gravity stiffness". 
ROMANIAN JOURNAL

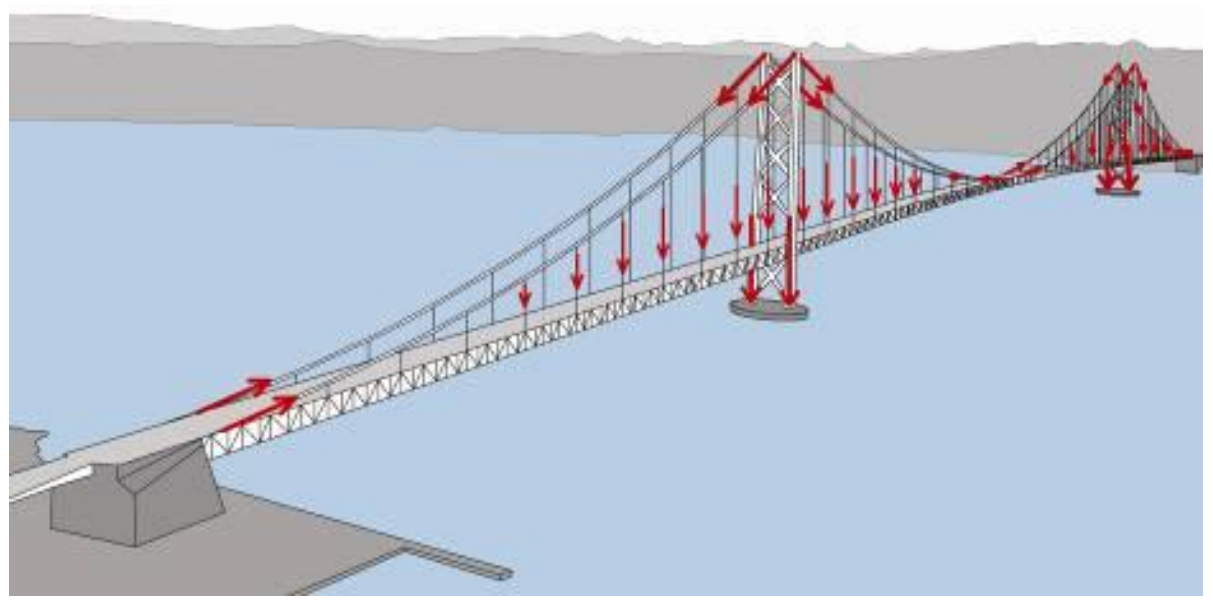

Figure 2. Suspension bridge scheme with force flow

For comparatively short spans, such as those of 19th century suspension bridges, the two stiffnesses are comparable and both the deck and the cables carry significant shares of the live loads: the deck is viewed as the "stiffening girder". For increasing spans, as the deck size does not depend directly on span, the relative deck stiffness decreases rapidly and any significant stiffening role by the deck for global loads is lost: the deck acts merely as the element collecting live loads and distributing them between the hangers. This trend is illustrated in Figure 3, which shows the proportion of the total applied load carried by the deck as a function of span length for two different bridge deck girders.

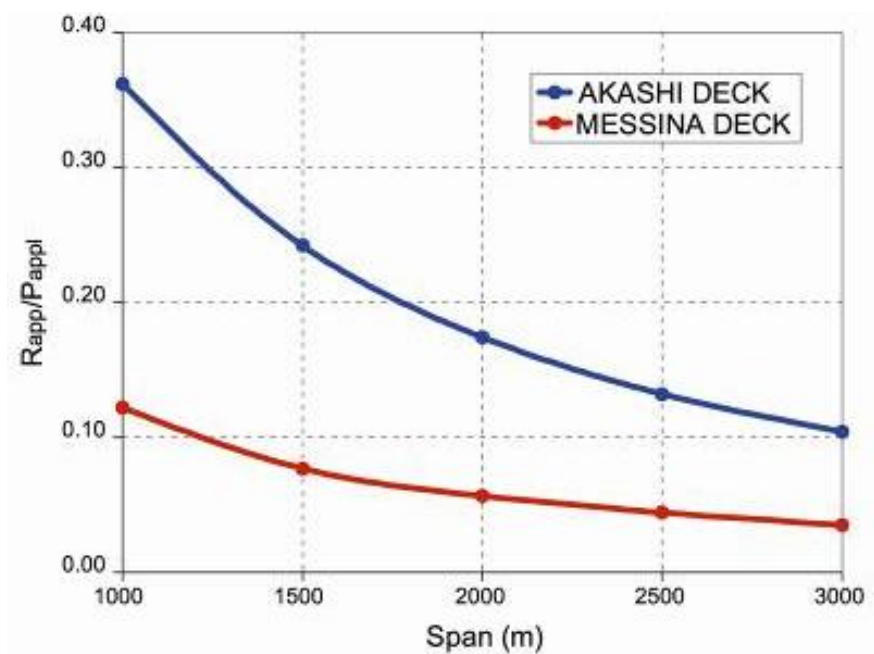

Figure 3. Proportion of load carried by deck girder as a function of span 
ROMANIAN JOURNAL

OF TRANSPORT INFRASTRUCTURE

Hence, the main cable is the element conferring stiffness to the bridge, the real backbone of the structure. This stands for in plane behaviour as well as for rotational or out of plane response: e.g. a decisive parameter in determining the bridge "torsional", or to say better "rotational", stiffness is the distance between the main cable suspension planes, as this provides the lever arm to transfer the deck rotation into vertical cable forces and stiffness.

But although the transfer of stiffness towards the main cables is the most obvious consequence of span increase, it is not the only one. Other aspects emerge which form the basis of what shall be referred to herein as "the problem of scale", underlining how the size of the bridge changes its behaviour not only quantitatively but also qualitatively. Such scale aspects are manifold, with a few of them becoming dominant for feasibility and design. For simplicity, these have been collected into the following two issues which are different in nature although derived from the same source; the first is concerned with overall sustainability and financial feasibility, and the second with very fundamental structural safety:

- Scale issue one: cable steel self weight and quantity

- Scale issue two: dynamic properties and aeroelastic stability

\section{SCALE ISSUE ONE: CABLE STEEL SELF WEIGHT}

Figure 4 shows the variation in cable tension with span due to different loading components for a road suspension bridge with steel orthotropic plate box deck. Similar results stand for other configurations or rail loads [4].

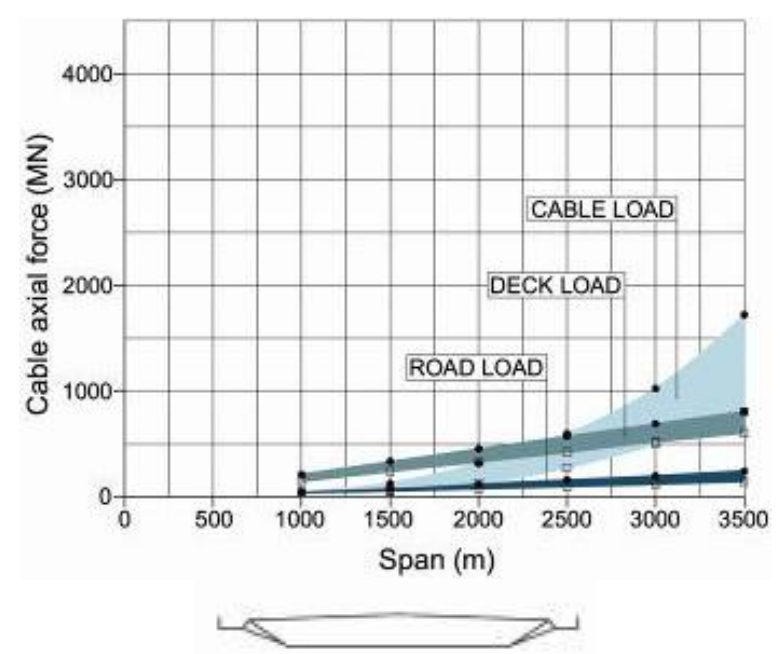

Figure 4. Variation in cable tension with span due to different loading types 
It can be seen that for spans around one thousand metres the deck weight is the largest component of cable tension, with significant contributions from road loads and less from the cable self weight. For growing spans the increase in the deck contribution is, as expected, proportional to the span. The road load contribution is less than proportional, as for very large spans average live load intensities decrease, due to standard probability considerations. By contrast, the cable self weight contribution increases more than proportionally with increasing span. For spans over 1500 and 2000 metres, the contribution of cable self weight to cable tension surpasses the effect of road loads, between 2000 and 2500 metres it equals the contribution of the deck, and it becomes clearly the largest contribution for spans over 2500 metres.

This means that for super long spans the cable becomes the heaviest and most expensive component of the superstructure and the large cable size in turn results in higher sizes and costs for the towers, foundations and anchor blocks because these are all elements that support or restrain the cable weight and forces.

Limiting the cable weight is thus the most fundamental design target to be achieved to deal with the first large scale issue, so as to allow the overall sustainability and financial feasibility of a very large span bridge. As the cable weight stems from the loads it must carry and from the maximum allowed working stress in the steel wire, every effort must be devoted to:

- Selecting deck configurations which are as lightweight as possible, adopting high strength steels in order to reduce weight where appropriate.

- Keeping all deck fittings, surfacing and equipment at their lowest weight consistent with suitable performance.

- Adopting for the main cables steel wires of the highest material strength compatible with other required performance characteristics

- Careful selection of partial safety factors and working stress levels suitable for the specific case of a structure with very high self weight and dead load percentages.

- Adopting sag to span ratios as high as possible, consistent with other necessary performance requirements. 
ROMANIAN JOURNAL

OF TRANSPORT INFRASTRUCTURE

Fabio Brancaleoni

Concepts and new perspectives for long span bridges

\section{SCALE ISSUE TWO: DYNAMIC PROPERTIES AND AEROELASTIC STABILITY}

Having seen how cable stiffness varies with span and how it becomes progressively dominant for static behaviour, it is also clear the same to take place for the dynamic behaviour of the bridge, in relation to its inertial properties, namely the quantity and distribution of mass. Figure 5 shows the typical first mode frequencies of a super long suspension bridge, based on [4], which do not necessarily occur in the order listed:

- The first two lateral modes, a) symmetric and b) antisymmetric, are both associated with a lateral "pendulum" motion of the deck and cables, and are dominated by geometric stiffness. The symmetric lateral mode is usually the first absolute structural mode of a long suspension bridge.

- The first two vertical modes are c) symmetric and d) antisymmetric. Antisymmetric modes are dominated by geometric stiffness, while symmetric ones involve a higher participation of axial strain in the cables and hence of its axial stiffness. These modes are often referred to as "flexural" or "bending" modes because of the deflected shape of the deck. However, such terms can be somewhat misleading, since it is the cable stiffness and not the deck stiffness that is dominant, so the term "vertical" modes is preferred herein.

- The first two rotational modes are e) symmetric and f) antisymmetric. As for the vertical ones, the antisymmetric modes are dominated by geometric stiffness, while the symmetric ones involve a higher participation of axial strain in the cables. These modes, higher than the corresponding lateral or vertical modes, are often indicated as "torsional" due to the form of deck deformation, but again it is considered that such terms can be somewhat misleading, as the cable stiffness and not the deck stiffness is dominant. Therefore, the term "rotational" is preferred herein. 
ROMANIAN JOURNAL

OF TRANSPORT INFRASTRUCTURE

Fabio Brancaleoni

Concepts and new perspectives for long span bridges

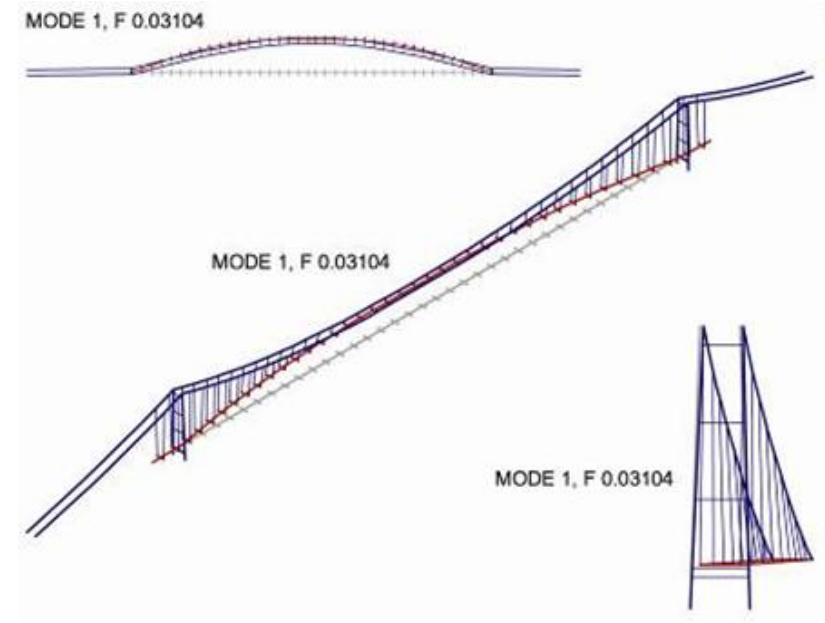

a - Symmetric lateral mode, $\mathrm{T} \approx 32 \mathrm{~s}$

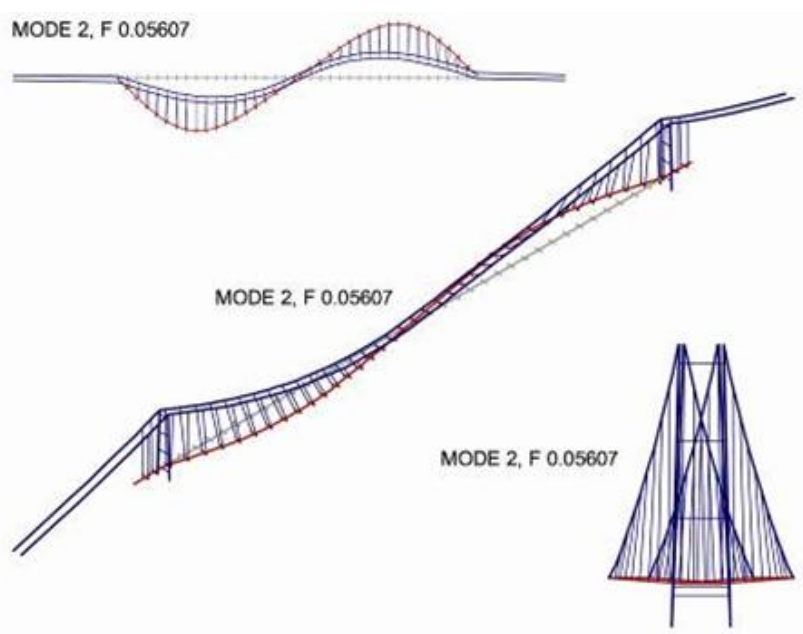

$\mathbf{b}$ - Antisymmetric lateral mode, $\mathrm{T} \approx 18 \mathrm{~s}$
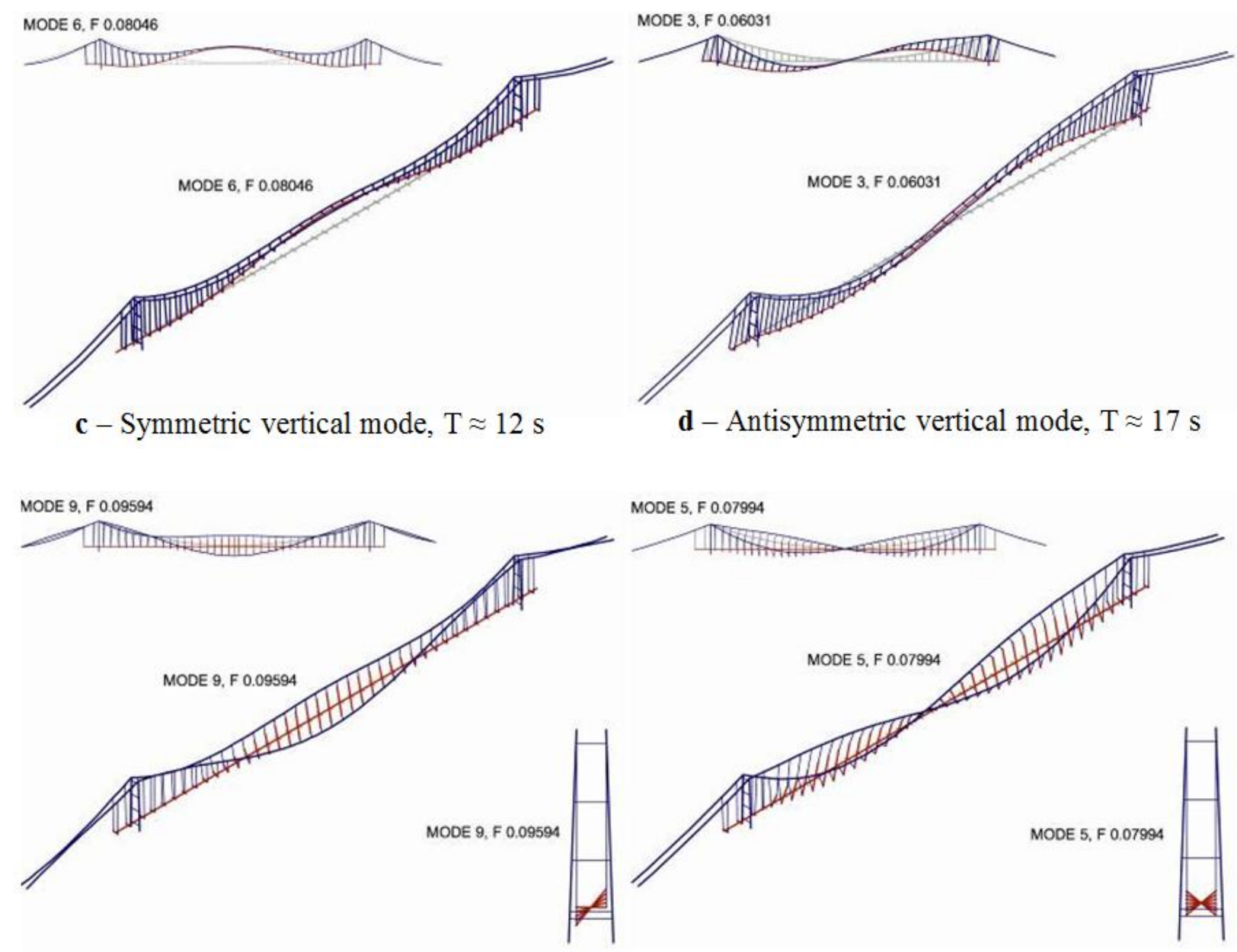

e - Symmetric rotational mode, $\mathrm{T} \approx 10 \mathrm{~s}$

f - Antisymmetric rotational mode, $\mathrm{T} \approx 12 \mathrm{~s}$

Figure 5. Main vibration modes for a super long span suspension bridge 
The main cable stiffness is dominant in defining the dynamic properties for any suspension bridge, as has also been shown for static behaviour. What changes the picture for very long spans is the fact that the main cables become the largest element for weight and mass, so that they also dominate the inertia distribution. In other words, the mode shapes and frequencies of a very large span suspension bridge become progressively more similar to those of standalone cables, while the effect of the other bridge elements becomes progressively smaller. This is of particular relevance for the vertical and rotational modes, whose frequencies become closer for increasing spans. At the limit, if the two main cables were in a stand-alone, perfectly restrained condition, the two modes would have the same frequency, corresponding to inphase and out-phase oscillations of the two identical perfect cables. For a given configuration and sag to span ratio, a number of factors, of different significance, contribute to maintaining a certain frequency separation between the two modes, the main ones being:

- The ratio between deck torsional and flexural stiffness, with high values of this parameter increasing the rotational frequencies. This parameter can be tuned in the design, although with more difficulty and less effectiveness for increasing spans.

- The different inertia distribution of deck and main cables. The cable mass is concentrated in the suspension cable planes, i.e. generally at the edges of the structure, while the deck mass is roughly evenly distributed between the cable planes. For vertical modes this means that the two inertial contributions do not vary with location. The opposite applies for rotational modes and, since the deck contribution is less significant than the cables, this leads with increasing span to rotational frequencies lesser and closer to vertical ones.

- The tower properties and specifically the ratio between its overall longitudinal flexural stiffness and its stiffness for rotations about its vertical axis. The former participates in vertical bending modes of the bridge, and the second, which is usually higher due to the connections between the tower legs, participates instead in bridge rotational modes. 
ROMANIAN JOURNAL

OF TRANSPORT INFRASTRUCTURE

- The longitudinal stiffness of the connection between the main cables and the deck, significant when the main cables are connected directly to the deck at mid-span via triangulated steel struts or ropes.

This trend to decreasing frequency ratio with span is illustrated in Table 1, which shows the rotational/vertical frequency ratios for some existing bridges and the proposed Messina Bridge. While the existing bridges have a ratio well over two, with a minimum of 2.35 for the largest existing span of the Akashi Bridge, the value for Messina reduces to about 1.36.

Table 1. Rotational/vertical frequency ratios

\begin{tabular}{|c|c|c|c|}
\hline Bridge & Span $(\mathbf{m})$ & Deck Type & Frequency Ratio \\
\hline Severn & 988 & Box & 2.65 \\
\hline Humber & 1410 & Box & 2.80 \\
\hline Storebaelt & 1624 & Box & 2.79 \\
\hline Akashi & 1991 & Truss & 2.35 \\
\hline Messina & 3300 & Multi-box & 1.36 \\
\hline
\end{tabular}

Such rotational/vertical frequency ratio, together with the deck aerodynamic properties, determines the wind response properties of the bridge for the most dangerous possible form of aeroelastic instability, i.e. classic flutter, which arises due to coupling of rotational and vertical modes. The closer the modal frequencies, or in other words the lower the above frequency ratio, the lower is the wind speed at which instability occurs. Existing bridges tend to exhibit critical wind speeds for flutter of the order of $60-70 \mathrm{~m} / \mathrm{s}$. Reaching similar values for a bridge with a frequency ratio below 1.50 is extremely challenging.

This then defines the second main scale issue which dominates the design of very long spans, namely achieving adequate flutter stability for a bridge characterised by intrinsically close rotational and vertical mode frequencies and shapes. While for medium to large spans it is possible, up to a certain extent, to improve stability by making changes to structural parameters, e.g. modifying the deck stiffness to increase frequency ratios, for very large span the main solution must be to improve the deck aerodynamic properties. That is to leave aside for the moment other possible countermeasures, such as introducing active control devices, which still require further research, particularly into providing adequate 
robustness and reliability, before they can be used on such a major piece of infrastructure.

Minor, but nevertheless cost important, targets connected with the static wind behaviour also include the achievement of low aerodynamic drag so as to minimise lateral wind forces, which are the main influence on lateral tower behaviour (in addition to seismic effects), and of low aerodynamic moment so as to minimise the cross-fall slope of the road and rail platforms. Such targets must of course be obtained together with achieving minimum weight, in order to cope with the first scale issue as well. Needless to say, several of these factors are contradictory.

For a better understanding, in the following it is given a short outline of the rationale for two degree of freedom instability phenomena, while other forms of instability are more widely discussed e.g. in [4]. When a body, here a bridge deck, is subject to a wind speed of velocity $V$ the pressure distribution and friction action due to the fluid produces on the body a resultant force that can be resolved into in a drag force $F_{D}$ parallel to the wind and a lift force $F_{L}$ normal to the wind direction. An aerodynamic moment $M_{A}$ is also applied to the body, acting around a reference point $C$ where the $F_{D}$ and $F_{L}$ forces are applied. The Drag, Lift and Moment forces have the following expression:

$$
\begin{aligned}
& F_{D}(\alpha)=\frac{1}{2} \rho V^{2} S C_{D}(\alpha) \\
& F_{L}(\alpha)=\frac{1}{2} \rho V^{2} S C_{L}(\alpha) \\
& M_{A}(\alpha)=\frac{1}{2} \rho V^{2} S B C_{M}(\alpha)
\end{aligned}
$$

where $\rho$ is the air density, $V$ is the air velocity, $S$ is a reference body surface, $B$ is a reference body dimension, $C_{D}(\alpha), C_{L}(\alpha), C_{M}(\alpha)$ are the Drag, Lift and Moment coefficients which are functions of the angle of attack $\alpha$ of the wind direction in respect of a reference axis. It can be seen that, if these decks have wing-like profiles, they have similar lift and moment coefficients, whose values increase almost linearly with the angle of attack, as in the case of an aerofoil or a flat plate. The $C_{L}(\alpha)$ and $C_{M}(\alpha)$ curves show a positive slope, while the drag $C_{D}$ is low.

Now, if the body is moving with a given velocity across the wind flow, the forces applied to the body are functions of the relative velocity $V_{R e l}$ of the wind in respect to the body and the expressions given can be applied introducing $V_{\text {Rel }}$ instead of $V$. Drag, Lift and Moment forces become functions of the motion of the deck as well.

The aerodynamic forces, being dependent on the generalized displacement field, become similar in formulation to the structural elastic forces, 
ROMANIAN JOURNAL

OF TRANSPORT INFRASTRUCTURE

which are also functions of the displacements, and give rise to an aerodynamic stiffness matrix, to be added to the structural stiffness. In turn, the aerodynamic forces which depend on the velocity, are similar to the structural damping forces and give rise to an equivalent damping matrix. For this reason, when a bridge is subjected to a generic wind speed $V$, its natural frequencies are also functions of the aerodynamic characteristics of the deck section and of wind speed through the equivalent aerodynamic stiffness, while the bridge overall damping is a function of the aerodynamic shape of the deck, through the equivalent aerodynamic damping.

Focussing attention on rotations, one can see that an increment of deck rotation produces an increment of aerodynamic moment applied to the deck. The aerodynamic moment increases linearly with the angle of attack and has the same sign as the deck rotation angle.

On the other hand, when a rotation is imposed on the deck, an elastic restoring moment arises, mainly due to the elastic contribution of the main cables and to a lesser extent to the deck torsional stiffness. An elastic positive torsional stiffness $\left(k_{t-s}\right)$ is the elastic restoring moment divided by the deck angle of rotation, but with opposite sign. This equivalent aerodynamic stiffness, proportional to the slope of the moment aerodynamic coefficient, can be expressed through the following relation:

$$
k_{t-a}=-\frac{1}{2} \rho S V^{2} \frac{\partial c_{M}(\alpha)}{\partial \alpha}
$$

where $\frac{\partial C_{M}(\alpha)}{\partial \alpha}$ is the derivative of $C_{M}(\alpha)$.

When no wind is applied to the bridge, the first torsional frequency of the bridge is related to the structural parameters only; i.e. the inertia of the bridge and the torsional stiffness $k_{t-s}$. When the wind is blowing onto the bridge deck, the overall torsional stiffness $k_{t-t}$ is made of structural and aerodynamic contributions:

$$
k_{t-t}=k_{t-a}+k_{t-s}
$$

with $k_{t-a}$ being negative and proportional to $V^{2}$. For this reason, $k_{t-t}$ decreases with the wind velocity, together with the first torsional frequency which is related to the ratio between torsional stiffness and bridge moment of inertia (deck+cables). Fig. 6 shows how the first torsional frequency of a bridge decreases with the wind speed $V$. 
ROMANIAN JOURNAL

OF TRANSPORT INFRASTRUCTURE

Fabio Brancaleoni

Concepts and new perspectives for long span bridges

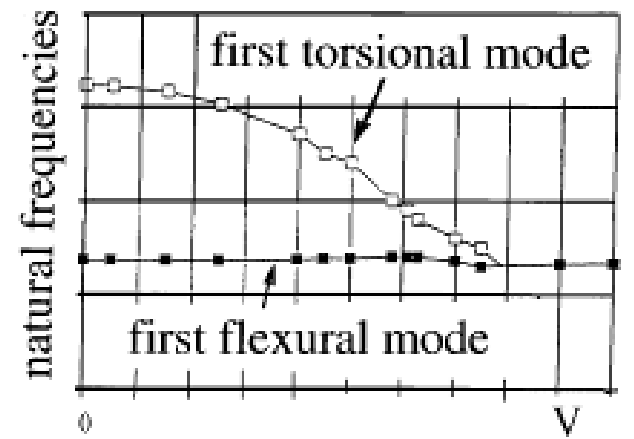

Figure 6. The first torsional frequency of a bridge decreases with the wind speed

On the other hand, the first vertical frequency is not practically changing with wind speed, so as wind speed increases the first torsional frequency can become equal to first vertical frequency. When this happens, a synchronized vertical and torsional motion may take place. In this type of motion the aerodynamic force (lift force) can introduce energy into the deck and can produce increasing amplitudes, giving rise to the two degree of freedom instability: coupled flutter. The wind velocity producing this synchronization mechanism is the critical flutter velocity.

Before entering the description of how this can be handled for super long bridges, it is useful to comment on how the matter has been tackled for some existing bridges. As it is well known, the problem of suspension bridges aerodynamic instability was dramatically brought to light by the 1940 Tacoma Narrows Bridge collapse. It is worth noting that the Tacoma designers had indeed understood that the deck is a secondary element for global static behaviour, seeking low weight solutions. The Tacoma deck abandoned the classic truss configuration of the $19^{\text {th }}$ and early $20^{\text {th }}$ century bridges and was simple, statically effective and light, comprising only two shallow I-beams in the suspension planes, plus small transversal I-beams, to carry the road platform. While statically effective, such a geometry exhibits extremely negative aerodynamic properties, and these allowed the build up of large amplitude oscillations, leading to the collapse under a wind speed lower than $20 \mathrm{~m} / \mathrm{s}$. The immediate reaction to the problem was the return to large truss decks providing high torsional stiffness. Very many bridges with such decks were built in the second half of the $20^{\text {th }}$ century, often also introducing minor aerodynamic measures into intrinsically safe configurations. However, although truss decks can be made aerodynamically stable, they do not meet all the requirements 
stated by a long way. In the first place they are heavy, and secondly (and by no means negligibly) they exhibit high drag due to their large depth.

A significant step forward, for certain span ranges, was achieved with the adoption of an orthotropic stiffened plate streamlined closed box deck. Such a deck, used for the first time in 1966 for the Severn bridge (Figure 7), is very light-weight and exhibits good torsional stiffness thanks to the closed box shape, a low flexural stiffness due to the shallow depth, together with a very low wind drag. Such a configuration implies overall costs definitely lower than truss decks for similar spans, and has been extremely successful in the last forty years, having been adopted for a large number of bridges worldwide. This type of decks meets all the requirements for large spans except for the one that has been said to be of paramount importance. The flat wing shape and large solid lower surface results in high lift forces and thus hampers aerodynamic performance. In other terms, its intrinsic stability properties are good but not excellent; it is well known in aeronautics that a perfect wing suffers from two degree-of-freedom flutter instability. Orthotropic plate "wing" box decks are therefore the winning solution for spans up to about $1500 \mathrm{~m}$, but progressively lose their best properties for longer spans. Already for two of the existing longest span bridges with box decks, the Humber Bridge (1410 m, 1981) and the Storebaelt Bridge $(1624 \mathrm{~m}, 1998)$ it was necessary to increase the deck depth from the typical $3 \mathrm{~m}$ to about $4.50 \mathrm{~m}$, to increase the torsional stiffness and achieve a not exceptional critical flutter speed of about $60 \mathrm{~m} / \mathrm{s}$. Increasing the depth also results in a modest increase in drag and self weight.

It is believed that, if not impossible, a $2000 \mathrm{~m}$ span with such a deck would become comparatively complex, requiring a very large box and ultimately losing several of the positive aspects of this type of solution. This is confirmed by the solution adopted for the $1991 \mathrm{~m}$ span Akashi Bridge design. After carefully comparing different box deck schemes the designers decided to adopt a deep, torsionally stiff truss scheme, already shown in Figure 1. 
ROMANIAN JOURNAL

OF TRANSPORT INFRASTRUCTURE

Fabio Brancaleoni

Concepts and new perspectives for long span bridges

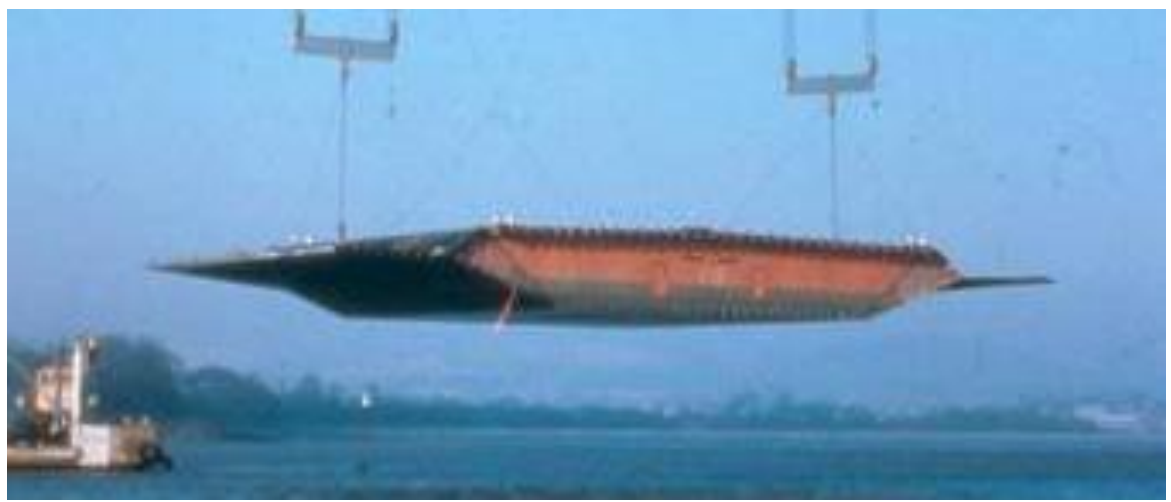

Figure 7. Severn Bridge deck (1966), depth $\sim 3 \mathrm{~m}$, self weight $\sim 0.3 \mathrm{t} / \mathrm{m}^{2}$

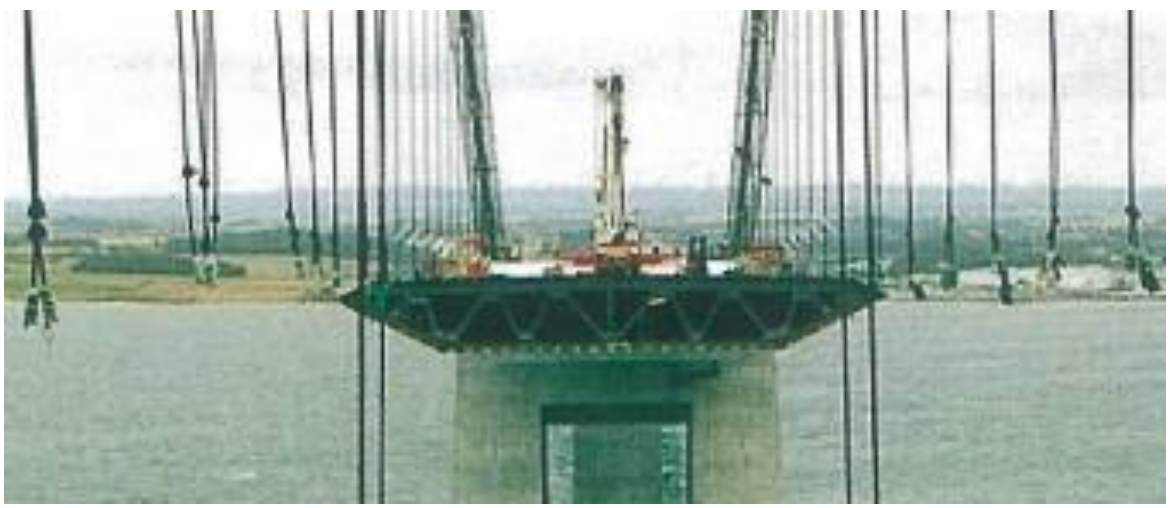

Figure 8. Storebaelt Bridge deck (1998), depth $\sim 4.5 \mathrm{~m}$, self weight $\sim 0.35 \mathrm{t} / \mathrm{m}^{2}$

The weight issue was already well understood and important enough to require the use of high strength steel for the truss structure, not so much to save on the deck itself but to minimise the cable size as much as possible. The resulting design achieved an average self weight of about $0.85 \mathrm{t} / \mathrm{m}^{2}$, which is excellent for a large truss but much higher than the about $0.30 \mathrm{t} / \mathrm{m}^{2}$ which would be typical of a Severn type steel box deck.

On the grounds discussed one can conclude that these two among the current longest spans in the world, Storebaelt and Akashi, are based on bridge decks close to the limit of effectiveness in their own class. While precise boundaries do not exist in structural design, it is considered that either deck type would become unwieldy for spans over $2000 \mathrm{~m}$ and result in very high costs to achieve adequate performance. Neither is a practical solution for spans over $2500-3000 \mathrm{~m}$.

As the ineffectiveness of structural stiffness on super long span has been stated already, the way forward is hence to work on the deck aerodynamic properties: bearing in mind what has been just presented, a straightforward concept to increase the flutter velocity is to reduce the value of the $C_{M}(\alpha)$ 
coefficient and, moreover, of its derivative $\frac{\partial C_{M}(\alpha)}{\partial \alpha}$. If the value of this derivative was zero, no variation of the torsional frequency with the wind speed would occur, and no flutter instability would occur. However care must be taken in reducing this derivative because it must in any case remain positive for single degree of freedom stability here not discussed, see [4]. The chronicle of how concepts and solutions evolved to meet such a challenging goal for the $3300 \mathrm{~m}$ span of the Messina Bridge is presented in the next paragraph.

Before advancing to such main topic of this paper it is considered useful giving a short comment on other aspects, that are important but not dominant for long span bridges:

- Seismic response.

- Serviceability, in particular for rail loads.

About seismic behaviour, the main factor for the superstructure design is that the main bridge modes, with high participation factors, are not coincident in frequency with the seismic ground motion. As already seen, first modes involving the cables and the deck have vibration periods from about 10 to over 30 seconds. This is a range in which the seismic input energy is virtually nil. Local deck or cable modes with periods of only a few seconds (close to natural seismic input periods) are so high that the participation factor is practically zero, so no significant response occurs. In other words, the bridge superstructure acts as a mechanical filter for ground motion: while the soil shakes, the bridge towers flex and the body of the superstructure stands still. The only elements of a long suspension bridge superstructure which are sensitive to seismic excitation, with local modes with periods of a few seconds and significant local participation factors, are the towers. Typically, the longitudinal tower design is dominated by the simultaneous presence of the high axial force and of the flexure due to earthquake loads, while the transversal one is dominated by axial force plus wind. The seismic actions are also important for the design of foundations and anchor blocks, but the problems they involve do not differ from those of other classes of massive large concrete structures on ground or underground, without becoming specific or dominant for suspension bridges [4]. 
ROMANIAN JOURNAL

OF TRANSPORT INFRASTRUCTURE

Fabio Brancaleoni

Concepts and new perspectives for long span bridges
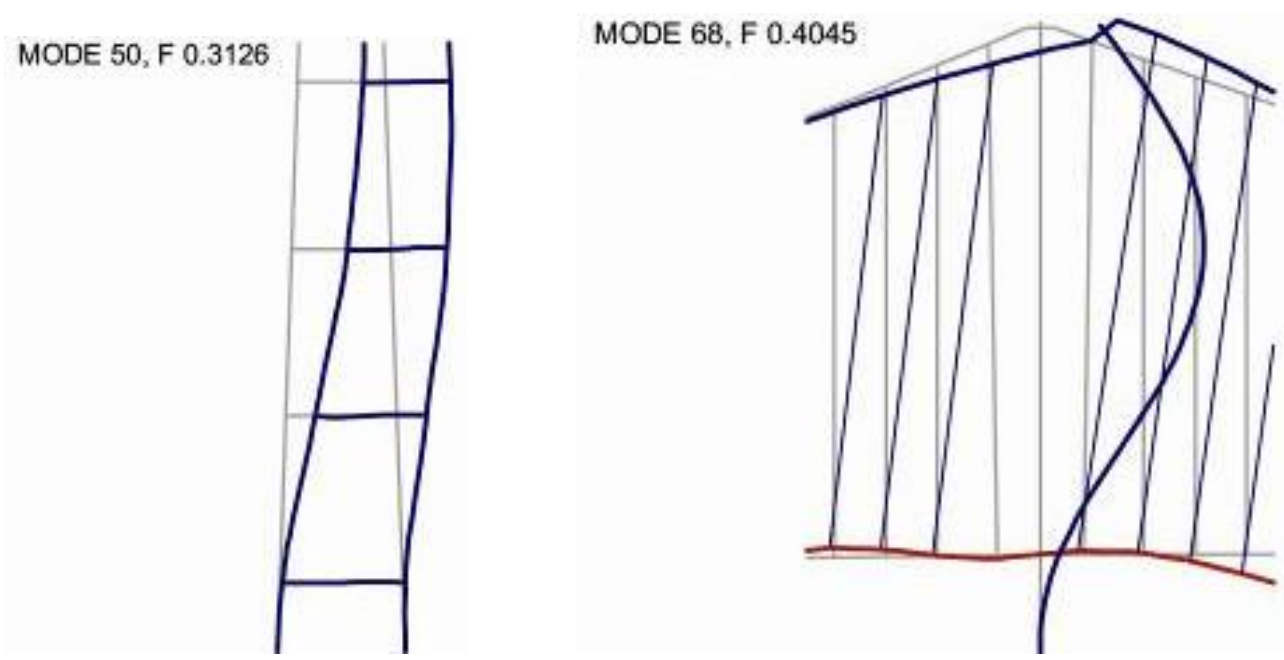

Figure 9. Transversal $(\mathrm{T}=3.2 \mathrm{~s})$ and longitudinal $(\mathrm{T}=2.47 \mathrm{~s})$ modes of the towers, Messina Bridge.

Regarding serviceability, the deformability of suspension bridges and its implications for railway runnability is a classical engineering problem in the technical and scientific sphere. That suspension bridges are flexible structures, undergoing significant displacements under heavy loads, is something of which designers have always been aware since the beginning of the modern age of long span steel bridges. This is specifically true for railway loading, which is characterised by large total loads applied over comparatively short lengths.

The problem was analysed in detail already in [5], showing how the deformability of suspended bridge decks in terms of longitudinal slopes strongly depends on the span length, and also how with increasing span length the geometrical stiffness due to the main cable tension gradually becomes more important in the deck-cable interaction, progressively reducing the deck longitudinal slopes. In particular, it was shown how significant and maybe excessive longitudinal gradients could occur in structures up to about $1000 \mathrm{~m}$, thus justifying the historical concerns with rail suspension bridges, while for longer spans at around $1500 \mathrm{~m}$ the slopes decrease significantly, and the problem could be considered minor over $2000 \mathrm{~m}$.

\section{EVOLUTION OF LOW-WEIGHT, LOW-LIFT HIGHLY STABLE DECKS}

This section discusses how the final deck solution for the Messina deck was reached, in the period from the early seventies to the early nineties to be 
ROMANIAN JOURNAL

OF TRANSPORT INFRASTRUCTURE

subsequently optimised and improved [4], [6], [7]. Already in the seventies it had been appreciated that working on the structural side of the deck properties, e.g. by providing sufficient torsional stiffness to achieve aerodynamic stability by adopting a truss type deck, was a dead end towards feasibility for a three kilometres span. That Severn type box decks could not achieve sufficient stability at such a span was also patent. It was therefore understood to be necessary, on the contrary, to work on the aerodynamic properties of the deck, reducing aerodynamic forces at birth.

As to how, one should remember that, immediately after the Tacoma collapse in 1940, the idea of inserting voids or gaps into bridge decks to reduce aerodynamic forces arose in the suspension bridge world. Such measures were adopted, for example, for the Tagus Bridge in 1966, among others, adopting grid strips within the road platform. While the idea in itself was not new, the early applications of this concept were rather simplistic.

A genuine evolution of the concept was proposed in the early seventies by W.C. Brown with the idea of combining low weight Severn type box decks with voids: the so called "vented deck" concept. The scheme was based on the adoption of several small boxes with intermediate voids, closed by grids.

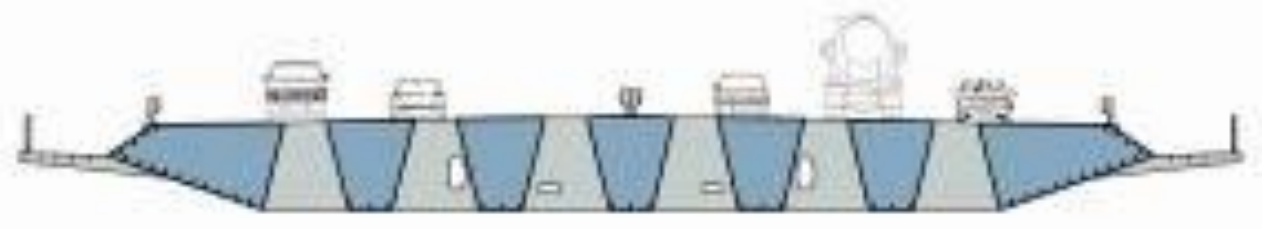

Figure 10. The "vented deck" concept

When W.C. Brown started his collaboration with the Messina design group in the late seventies, the vented deck concept was adapted to the road and rail bridge challenge, resulting in the configuration shown in Figure 11: a "double-decker", with the rail platform at the lower level, connected via a hammer strut to the upper road platform, formed by numerous small steel boxes with intermediate voids closed by grids, plus inclined ropes to connect the two levels and stiffen the whole. 
ROMANIAN JOURNAL

OF TRANSPORT INFRASTRUCTURE

Fabio Brancaleoni

Concepts and new perspectives for long span bridges

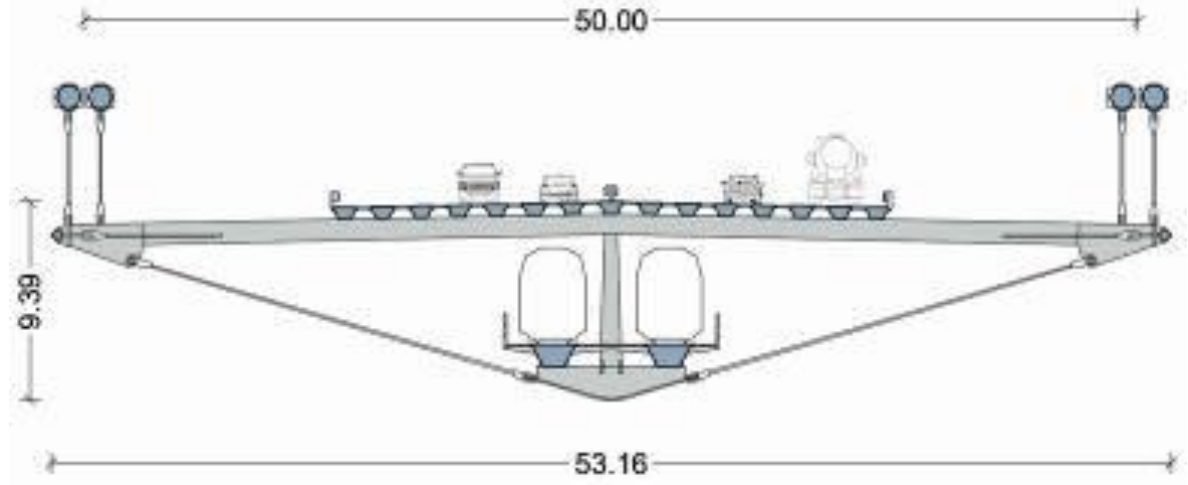

Figure 11. Messina bridge deck (1977 design), depth $\sim 12 \mathrm{~m}$, self weight $\sim 0.45$ $\mathrm{t} / \mathrm{m}^{2}$

Thus for the first time it was demonstrated, also through wind tunnel testing, that ensuring adequate stability on a three kilometre span was indeed possible. Nevertheless, this configuration possessed a number of drawbacks and non-optimal solutions, such as the presence of grids on the running surface, a structure complex in itself and unwieldy for maintenance. Also, from an aerodynamic standpoint, although effective, the void distribution was uniform across the deck width and hence intrinsically non optimal and the double deck configuration exhibited a moderately high aerodynamic drag.

With the progress of the activity the early eighties, immediate attention was devoted to improving the scheme. The main new concepts were:

- "Collecting" the numerous small boxes and gaps into a fewer, larger ones.

- As a considerable distance between cable planes was independently needed, the road and rail decks were located at the same level, using the lateral space available.

These were the fundamentals of an intense and challenging period of studies and optimization which lasted almost ten year, whose steps are not presented in detail but that can be given but a glimpse though the sketches and schemes in Figure 12. 
ROMANIAN JOURNAL
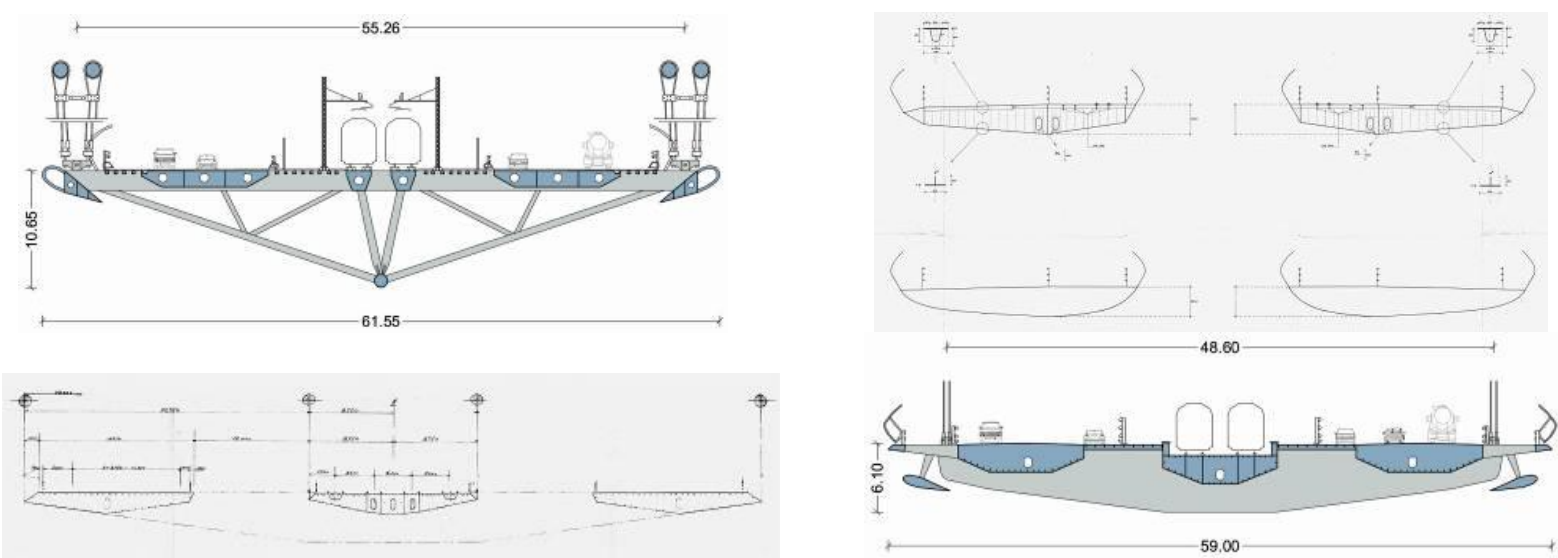

Figure 12. Messina deck development, 1983 - 1991

This process was concluded with the fundamental result of the 1992 design, shown in the following figure, comprising two railway tracks and six running road lanes on solid surfacing. Weight and stability are excellent, with a critical wind speed over $80 \mathrm{~m} / \mathrm{s}$. Furthermore, the deck is equipped with external windscreens to protect the traffic from direct wind action. These windscreens incorporate small horizontal aerofoils that are the evolution of the larger ones shown in the previous figures.

This multiple deck concept was afterwards still more perfected in details for fatigue, fabrication an runability until the present final design completed in 2011, but never changed in concept, becoming an accomplishment of general effectiveness and interest toward even larger bridge spans, that can find useful application throughout the world.

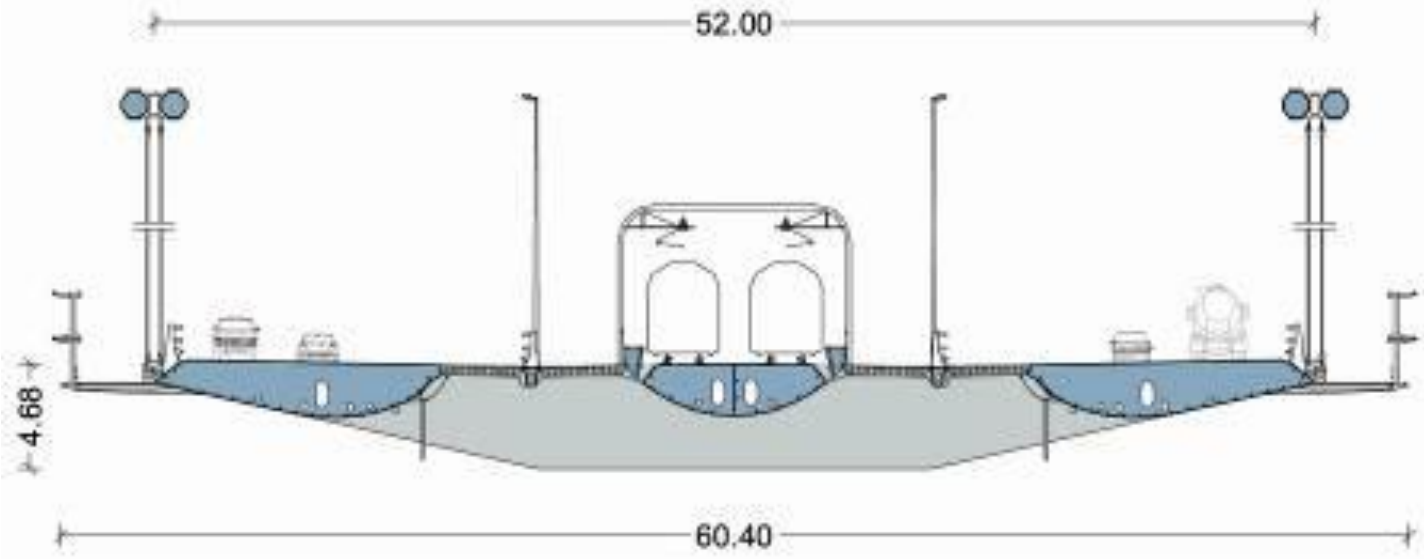

Figure 13. 1992 Messina design $\sim 4.7 \mathrm{~m}$, self weight $\sim 0.35 \mathrm{t} / \mathrm{m}^{2}$ 


\section{THE WAY FORWARD}

When the concept for the Messina bridge deck was known to the international bridge community in the eighties and nineties, interest arose immediately and designers around the world started considering its adoption for new projects.

This brought not only to several studies and concepts, but also to actual applications for construction: today a number of bridges exhibits deck solutions that can be considered derived from the Messina experience, see Figure 14, though not all of them, in the opinion of the author, did exhibit structural characteristics such to justify in full the adoption of this innovative solution for the deck. Among them the second bridge in the world, the $1650 \mathrm{~m}$ span Xihoumen, and the $1545 \mathrm{~m}$ Yi Sun-sin Bridge, where the adoption of a twin deck appears instead well justified. Yi Sun-sin is at present the fourth longest bridge in the world, to be soon surpassed by the $1550 \mathrm{~m}$ Izmit Bridge in Turkey, where a more traditional single box deck was adopted, with the significant depth of $4.75 \mathrm{~m}$, to increase the torsional stiffness and achieve adequate stability. In the scenario described one can conclude that in the near future:

- Cable stayed and suspension bridges shall both be competitive on spans of the order up to $1100-1200 \mathrm{~m}$, either with single box orthotropic plate decks.

- Larger span shall still be the domain of suspension bridges, with single box deck competitive until the order of 1500 - 1600 m spans, but with multiple box a valid alternative already over $1400 \mathrm{~m}$. Hybrid may appear, in specific cases.

- Over $1500 \mathrm{~m}$, suspension bridges with multiple box decks are the way forward, to reach a surpass the $2000 \mathrm{~m}$ limit, to take the record from the Akashi Kaikyo Bridge.

Once given such last bold statement, the obvious question arises: where and when one such technically and financially challenging project shall become reality? Besides the now suspended Messina Strait Crossing project, many studies and proposals for super long spans have been carried out worldwide: among them the Sunda Strait Crossing in Indonesia, the Ise Bay in Japan, even a futuristic Gibraltar Strait Crossing. Though, if one should indicate a present situation coupling a precise transportation need and an adequate economy one likely candidate is the so called "Ferry Free" E39 project in Norway, where at least three fjords or straits call for super long crossings. Figure 16 shows as an 
ROMANIAN JOURNAL

OF TRANSPORT INFRASTRUCTURE

Fabio Brancaleoni

Concepts and new perspectives for long span bridges

example one of the decks under study for a $2800 \mathrm{~m}$ suspension bridge on the Sulafjorden. This is not all. As the marine environment of the area is comparatively protected and waves to an extent limited, even more daring and innovative solutions are being studied as feasible: suspension bridges with floating foundations, making use of the experience in off-shore deep sea oil platforms, see Figure 17. Which shall we see first ? The beauty of the future is that it must still come.
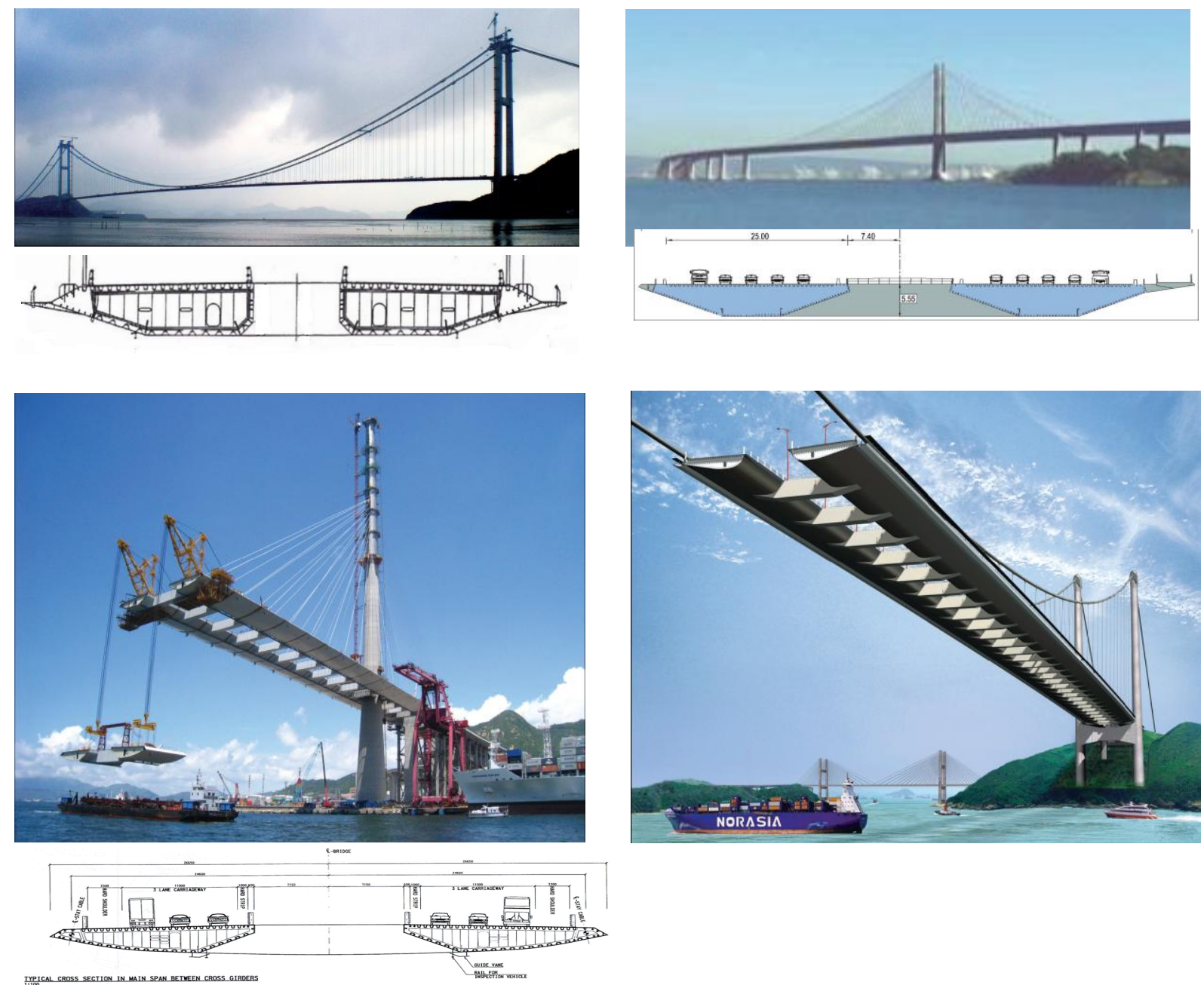

Figure 14. Clockwise: Xihoumen Bridge (China 2009), New Oakland Bridge (USA, 2013), Tsing Lung Bridge (Hong Kong, design),

Stonecutters Bridge (Hong Kong, 2009). 
ROMANIAN JOURNAL

OF TRANSPORT INFRASTRUCTURE

Fabio Brancaleoni
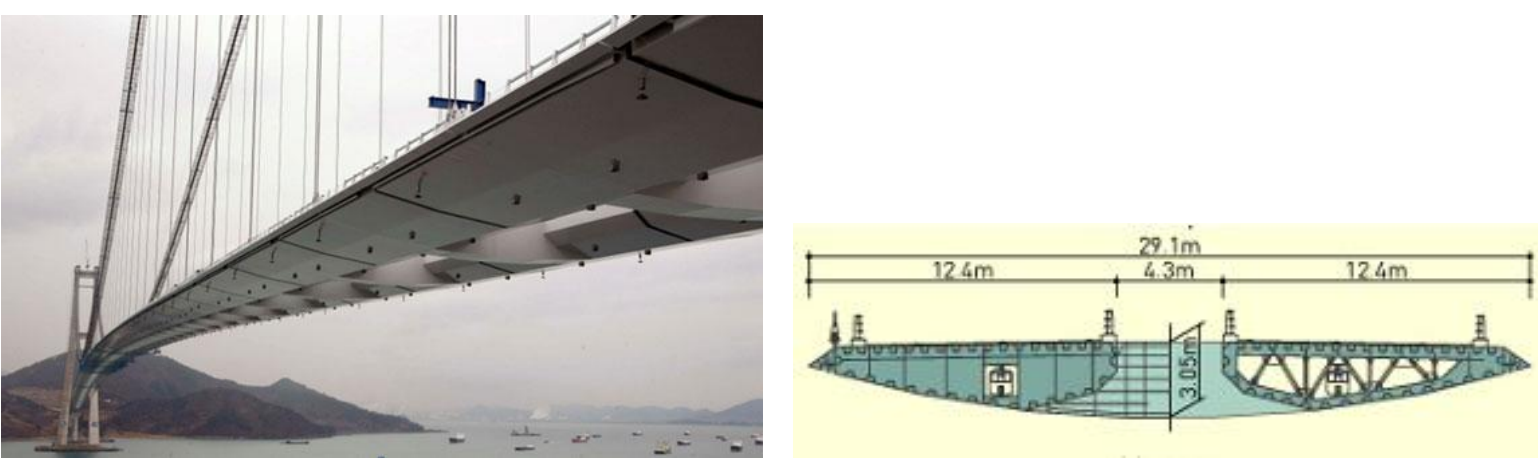

Figure 15. Yi Sun-sin Bridge (South Korea, 2012)

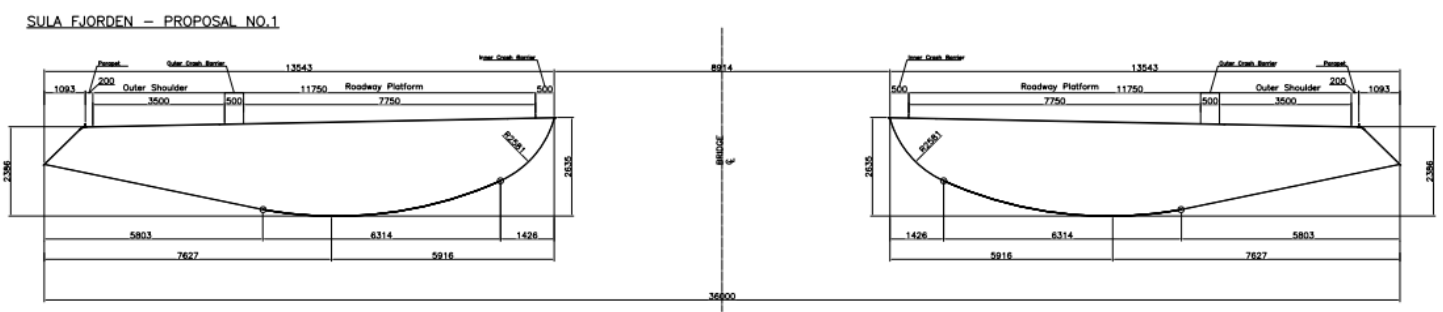

Figure 16. "Ferry-free E39", Norway, studies for a 2800 m suspension bridge deck

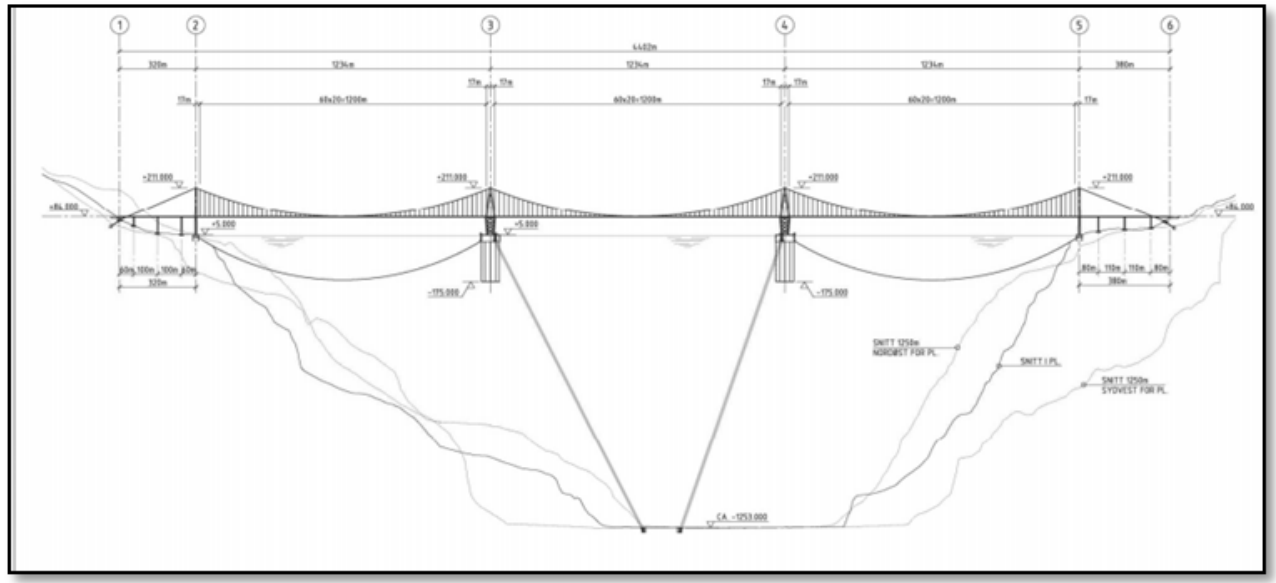

Figure 17. "Ferry-free E39", Norway, floating foundation suspension bridges 
ROMANIAN JOURNAL

OF TRANSPORT INFRASTRUCTURE

Fabio Brancaleoni

Concepts and new perspectives for long span bridges

\section{REFERENCES}

[1] N. GIMSING: “Cable Supported Bridges, Concept and Design”, WILEY-VCH, 2 edition, 1998.

[2] L. HAUGE, H. ANDERSEN: “Longer ....”, Keynote Lecture, IABSE Symposium, Londra, 2011.

[3] S. KITE: "Pushing the Limits of Cable Stayed Bridges", Sixth Symposium on Strait Crossing, Bergen, 2013.

[4] F. BRANCALEONI et alii: "The Messina Strait Bridge, a Challenge and a Dream", CRC Press, 2009.

[5] F. BRANCALEONI: „Verformungen von Hängebrücken unter Eisenbahnlasten“, Der Stahlbau, Darmstadt, 1979.

[6] F. BRANCALEONI: "The Construction Phase and its Aerodynamic Issues", in Aerodynamics of Large Bridges, ed. A. Larsen, Balkema, 1992.

[7] F. BRANCALEONI, G. DIANA: "The Aerodynamic Design of the Messina Straits Bridge”, International Journal of Wind Engineering and Industrial Aerodynamics, $\mathrm{n}$. 48, 395-409, 1993.

[8] NORWEGIAN PUBLIC ROADS ADMINISTRATION \& THE REGIONAL COUNCIL FOR WESTERN NORWAY: "Ferry-free Coastal Route E39”, National Conference, Stavanger, 2011. 